\title{
Foucault e indigenciação - as formas de silenciamento e invisibilização dos sujeitos
}

\author{
Foucault and the impoverishment - the shapes of silencing and \\ invisibilization of subjects
}

Wellington Amâncio da Silva*

\begin{abstract}
Recebido em:04/2015
Aprovado em:10/2015
\end{abstract}

\begin{abstract}
Resumo: Este artigo apresenta uma proposta teórica e conceitual sobre formas de indigenciação para além dos aspectos econômicos na contemporaneidade. Escolhemos duas das suas categorias, a saber, a invisibilização $e \quad o$ silenciamento - como as condições discursivas e as práticas de constituição do sujeito indigenciado. Normalmente indigente é, grosso modo, um sujeito que vive em extrema carência material, ausência de condições mínimas de salubridade e conforto com meios próprios. No entanto, defendemos que há formas de indigenciação mais complexas sobre os sujeitos para além da objetivação econômica. Assim, apresentamos a partir de uma perspectiva arqueológica, Foucaultiana (2002, 2007, 2008, 2010), a indigenciação como um afastamento existencial onde a investidura da máquina da punição e da vigilância encontra-se "desinteressada". Disto, temos como hipótese que a indigenciação ocorre a partir de duas dimensões, a saber, a dimensão do silenciamento e a dimensão da invisibilidade. A primeira dimensão fundamentar-se-ia pela tríade: ausência de discurso, discurso como monólogo ${ }^{l} e$ discurso não considerado. Por sua vez, a segunda dimensão definir-se-ia pela tríade: sujeito inconveniente, sujeito ignorado e o não-sujeito.

Palavras-chaves: Foucault, indigenciação do sujeito, silenciamento, invisibilização, discursos.
\end{abstract}

Abstract: This paper presents a theoretical and conceptual proposal on ways to indigencing (indigenciation) beyond the economic aspects nowadays. We chose two of its categories, namely, the invisibility and silencing - as the discursive

* Mestrando em Ecologia Humana pela UNEB

Problemata: R. Intern. Fil. v.6, n. 3(2015), p 111-128 ISSN 2236-8612

doi:HTTP://dx.doi.org/10.7443/problemata.v6i3.24016 
conditions, and as the indigencing subject constitution practices. Usually indigent is roughly a guy who lives in extreme lack material, absence of minimum conditions of health and comfort with its own resources. However, we argue that there are more complex forms of indigenciação on subjects beyond the economic objectification. Thus, we present from an archaeological perspective, Foucault (2002, 2007, 2008, 2010), indigencing as an existential estrangement where the investiture of the machine punishment and surveillance is "disinterested". From this, we hypothesize that the indigenciação occurs from two dimensions, namely, the size of silencing and the size of invisibility. The first dimension would be based by the triad absence of speech, speech as speech monologue and not considered. In turn, the second dimension set would be by the triad subject inconvenient, ignored the subject and non-subject.

Keywords: Foucault, indigence-action of the subject silencing, invisibility, discourse.

\section{Introdução}

Dentre as múltiplas formas de silenciamento e de invisibilidade do sujeito, talvez, as que menos provocam interesse de pesquisa, sejam aquelas consequentes da indigenciação. Pergunta-se se tal desinteresse decorreria da "intangibilidade" do fenômeno: por sua "localização imprecisa", pela "volatilidade" da presença dos seus sujeitos, pelo seu aspecto "ficcional" absurdo, por tipo característico de alienação. Qualquer pesquisador perguntar-se-ia acerca do procedimento e das ferramentas de pesquisa para auscultar o silenciamento e trazer à luz o "fenômeno" da invisibilidade; parece haver aí uma incongruência intrínseca às formas de indigenciação, mas é essa incongruência, esse regime de aporia, essa opacidade. Ora, se o indigente é, grosso modo, um sujeito que vive em extrema carência material, ausência de condições mínimas de salubridade e conforto com meios próprios, seus significados estão circunscritos na dimensão do trabalho e do capital. De todo modo, esse indigente ainda é, geralmente, incluído num campo de generalidades cujo núcleo central é a loucura, em seus matizes; disso, o indigente também é representado como alienado em demasia da ordem social e histórica do mundo como um ser que "coexiste" em dimensões paralelas à realidade 
instituída, um espectro; aqui, para que fique claro, a indigencição é uma invenção do próprio discurso, ressignificando o humano a todo instante e ao longo da história, tendo como base a toda essa ressignificação, as rupturas, as descontinuidades pelas quais os sujeitos são submetidos. Os caminhos que levam o ser humano à indigenciação é o que nos interessa aqui - e sabemos que existem diversos níveis de indigenciados que envolvem até as dimensões mais subjetivas do ser; existem tipos parecidos, que dialogam, reforçam um ao outro; existem tipos distintos de indigenciados, mais difíceis de apreender $^{2}$, e estes são construídos através de um jogo de sentidos e representações que convencionalizam-se nos discursos - a este processo de invisibilização e silenciamento do ser que denominamos indigenciação, que sustenta-se em três dimensões discursiva, a saber, a do trabalho, da política e da sexualidade. Destarte, esclarecemos que não suscitamos aqui uma discussão apenas sobre o indigente comum, a formação discursiva desse sujeito que evoluiu conceitualmente desde a Antiguidade, ganhando algum status de asceta na Idade Média e se tornando o "imprestável", o lumpemproletariado após a Revolução Industrial - sujeito que é uma negação á dimensão "apenas" do trabalho. Queremos dar alguns passos à anterioridade do fenômeno indigência e buscar entender sua arqueologia, por meio dos sentidos que a constitui e tentar desconstruir seus estereótipos, naquilo que Fredric Jamerson denominou de "lugar de um superávit ilícito de significado" (1994, p. 33-34), isto é, do estereótipo impreciso do homem andrajoso, de roupa puída, pedinte, maltratado de aparência: forma-sujeito cuja imagem pedagógica - apesar do silenciamento imposto à sua voz humana, exorta-nos a não sê-lo. No entanto, mesmo construindo cotidianamente um distanciamento existencial da forma-indigente, atravessam nossas subjetividades discursos e práticas de indigenciação tais que vão, em maior ou em menor intensidade, nos atingindo, determinando-nos como vítimas, ou como reprodutores algozes. Portanto, temos como hipótese que indigenciação é um processo de silenciamento e invisibilização para daqueles que negam para si a adoção de tipos humanos existenciais constituídos discursivamente no âmbito geral tridimensional, a saber, do trabalho, da política e da sexualidade. $\mathrm{O}$ processo de silenciamento compõe a tríade: ausência de discurso, discurso como monólogo ${ }^{3}$ e discurso não considerado. Por sua vez, o

Problemata: R. Intern. Fil. v.6, n. 3(2015), p 111-128 ISSN 2236-8612 
processo de invisibilização estabelece tríade: sujeito inconveniente, sujeito ignorado e o não-sujeito. Consideramos como a causa principal da indigenciação, no século XXI, as dimensões e processos acima citados. Disso postula-se que a indigenciação é uma condição imposta que tem o caráter de loucura social, isto é, de uma anormalidade individual dentro da ordem coletiva; de uma alienação particular dentro do contexto social comum; de desligamentos aparentes, mesmo estando implicado à trama social.

\section{Itinerário de pesquisa}

Com efeito, propomos o procedimento arqueológico para buscar compreender a indigenciação no domínio das práticas dos discursos próprias, em seu jogo de regras, sobre os sujeitos através desses sentidos "axiológicos" e suas práticas de verdade em face da "complexidade que lhe é própria". Nessa definição, Foucault (2010) afirma que "a arqueologia busca definir [...] os próprios discursos, enquanto práticas que obedecem a regras [...] mas cuja opacidade importuna é preciso atravessar frequentemente para reencontrar, enfim, aí onde se mantém a parte, a profundidade do essencial." (p. 157) ${ }^{4}$.

Deste modo, não sendo um "método formalizador, nem interpretativo" (Ibidem p. 153), compreendemos que o procedimento arqueológico é uma análise das origens do conjunto dos enunciados que circulam nos discursos individuais ou reunidos, como saber instituinte sobre um objeto e que, por assim dizer, funda o próprio objeto em suas condições e possibilidades de existência, num conjunto de regras que determina-lhe uma veracidade discursiva, a partir de certos "indicadores de verdade" (2002, p. 27). Devemos nos ater a esse aspecto ontológico do sujeito, isto é, seu ser reconhecido, constituído e inteligível no âmbito dessa materialidade do discurso "na qualidade de monumento" do discurso, dessa ponte entre práticas discursivas constituintes e sujeito aí fundado, objetivado, edificado discursivamente, no âmbito de uma inteligibilidade condicionada ao reconhecimento da verdade. Para Foucault $(2001,2004,2010)$, é preciso saber os começos dos saberes sobre os objetos (sujeitos), levando em conta os

Problemata: R. Intern. Fil. v.6, n. 3(2015), p 111-128 ISSN 2236-8612 
cortes ou descontinuidades do discurso e como o sujeito "aparece com sua posição ambígua de objeto para um saber e de sujeito que conhece [...]" (2007, p. 430). Disso, a arqueologia, é compreendida por Foucault (2010) como um termo que pretende destacar " $[\ldots]$ o tema geral de uma descrição que interroga o já dito no nível de sua existência" (Ibidem, p. 149). Em nosso caso, ao investigarmos os sentidos atribuídos aos objetos (e aos sujeitos), a arqueologia da indigenciação indicaria as estruturas de sua plataforma discursiva, historicamente situada, socialmente aceita e reproduzida como veracidade - visto que há um discurso sobre determinado objeto e, em outro momento, outro discurso constituinte sobre o objeto; com efeito, está claro para nós um movimento de interesses rumo ao objeto bem como a constituir-lo em certos significados; por causa disso, antes é preciso saber que, segundo Foucault, o discurso é, pois, "constituído de um número limitado de enunciados para os quais podemos definir um conjunto de condições de existência" (Ibidem, p. 132-133). Por conseguinte, as formas-sujeitos são ressignificadas e reconstruídas dentro desses contextos discursivos; Assim, em vista das intercalações de sentidos e de representações entre os sujeitos indigentes, indigenciados e a loucura como discursos que os atravessa, pensamos estar diante de um elaborado conjunto de condições existenciais próprio. Dito isso, pretendemos com o procedimento arqueológico estudar as formas de indigenciação através dos discursos em ao menos dois aspectos: de onde provêm as práticas de silenciamento e de invisibilização do "sujeito". Queremos deixar claro que ao tratarmos de formas-sujeitos, abordamos-lhas diretamente, ao tratar dos indigenciados, o fazemos por meio de uma observação oblíqua na tentativa de, neste artigo, não tentarmos criar mais uma forma-sujeito, uma representação, um discurso de dominação.

\section{A forma-sujeito e a sua constituição histórica}

Foucault (2002, 2007, 2010) analisa as formas de pensamentos através dos discursos e como são postos em atos e enunciados pelos sujeitos em cada tempo histórico determinado. Os discursos são formas de articulação, entre os sujeitos, dos modos de ser e de saber em condição ao que pode ser dito ou não dito, num plano contextual, isto é, em dado local, situação e

Problemata: R. Intern. Fil. v.6, n. 3(2015), p 111-128 ISSN 2236-8612 
em face de direitos discursivos conquistados; segundo Foucault, de determinar "seu titular" (2010, p. 56). Por conseguinte, é de determinado saber constituído, saber esse incorporado como jogo de verdade pelo próprio sujeito (sujeito discursivo), que se pode tomar posição para enunciar seus significados, isto é, para articular conceitos, sentidos e representações acerca dos objetos, tomando-os num momento que é histórico, em sua forma estática de significação, defendendo-os de fora e para fora, bem como incorporando a si, constituindo-se por meio de certos discursos aos quais crê ter a chancela para articulá-los como verdades, num jogo que se define por possibilidades de utilização e de apropriação de conhecimentos e saberes suscitados pelos discursos - nestas condições os sujeitos são constituídos. Em outras palavras, o discurso é "um conjunto de regras anônimas, históricas sempre determinadas no tempo espaço, que definiram em uma dada época, e para uma área social, econômica, geográfica, ou linguística dada, as condições de exercício da função enunciativa". (Ibidem, 2010, p. 133).

Em síntese, os discursos são modos de objetivação: uma das finalidades pela qual se enuncia. Constituintes de representação, de agrupamento e de catalogação dos sujeitos, como imagens, formas, configurações em tipos similares e dessemelhantes a partir de "figuras" ("psiquiatria" ou "economia política" ou" história natural"), por exemplo (Ibidem, p. 154). Segundo Woodward (2000, p. 17-18):

\footnotetext{
[...] os discursos e os sistemas de representação constroem os lugares a partir dos quais os indivíduos podem se posicionar e a partir dos quais podem falar. Por exemplo, a narrativa das telenovelas e a semiótica da publicidade ajudam a construir certas identidades de gênero. Em momentos particulares, as promoções de marketing podem construir novas identidades [...].
}

Por sua vez, essas formas expressas e significantes de ser e estar do sujeito são subjetivadas pelos mesmos sujeitos - a subjetivação define a constituição do sujeito moderna; em outras palavras, também o discurso esvazia o objeto, trazendo para si um simulacro como subjetivação do objeto reduzido em ideia tal processo é uma forma de violência. Mas, esse instrumental não é perfeito: circula nos discurso e nele reside uma quase 
imperceptível anomia, isto é, um distanciamento intrínseco ao procedimento de apreensão da análise e uma simulação de aproximação equivocada pela significação: amalgama entre o eu do discurso e a alteridade do objeto. Nessa perspectiva de "história das idéias", "trata-se da disciplina das linguagens flutuantes, das obras informes, dos temas não ligados. Análise das opiniões mais que do saber, dos erros mais que da verdade; não das formas do pensamento, mas dos tipos de mentalidade" (Ibidem, 2010, p. 155). Mesmo sendo tudo o que possuímos para comunicar, os discursos são subjetivados sempre numa perspectiva em vias de um equívoco em si mesmos, para dizer e significar quem é o outro, ou para convencionalizar os sentidos de si. Um exemplo disso, consta num texto de Foucault:

Cometeríamos um erro, seguramente, se perguntássemos ao próprio ser da loucura, ao seu conteúdo secreto, à sua verdade muda e fechada em si mesma, o que se pôde dizer a seu respeito e em um momento dado; a doença mental foi constituída pelo conjunto do que foi dito no grupo de todos os enunciados que a nomeavam, recortavam, descreviam, explicavam, contavam seus desenvolvimentos, indicavam suas diversas correlações, julgavam-na e, eventualmente, emprestavam-lhe a palavra, articulando, em seu nome, discursos que deviam passar por seus. (2004, p.36).

As representações de uma alteridade impossível de ser enunciada com precisão - de saber seu ding an sich, a coisa em si -, só podem ser assumidas por sujeitos que adotem para si estas representações, como sujeitos constituídos por elas, como formas-sujeitos de um discurso. Desse sentido também, a loucura poderia ser tomada como uma metáfora ao hermetismo contido em determinadas tentativas de significar por meis dos discursos, como um problema relacionado à alteridade do objeto do discurso.

Isso ocorre porque há na linguagem, especialmente em seu aspecto inerentemente polissêmico, dimensões contraditas: os antagonismos da loucura em face da norma, o auge do "desatino" ordenado em "racionalidade" discursiva; pretensões desta norma em alcançar a loucura - por meio das assepsias das ideias, da descrição e da análise -, sem enlouquecer, isto é, de trazer algum registro decalcado da superfície desse objetoloucura, catalogar e descrever as Figuras da loucura como uma projeção daquilo que não deseja ser (Foucault, 2008, p. 251); as representações da alteridade do objeto, que se não possuir uma Problemata: R. Intern. Fil. v.6, n. 3(2015), p 111-128 ISSN 2236-8612 
linguagem, uma condições de oferecer inteligibilidade discursiva, ou de estar alienado do próprio discurso, é estudado em sua forma passiva, como uma ideia do que possa vir a ser seu objeto5: a forma sujeito indigenciado, (assim como do louco), ser que, por assim dizer, escapa dos modos de "vigilância" e "punição" (Foucault, 2012) - essas duas concisas expressões da norma-lidade, da racionalidade do Nouos.

Temos até aqui, a loucura em seu hermetismo despretensioso, a indigência como uma condição predominantemente econômica e os processos de indigenciação como representações e ao mesmo tempo como prática: discurso que tenta convencionalizar os sujeitos não claramente traduzíveis, de difícil apreensão em objetos e, ao mesmo tempo, procedimento de ostracização desses sujeitos que não se permitem objetivar - e aqui objetivar é muito menos alcançá-los por meio de alguma descrição, ou retirar-lhes algum sentido, mas, muito mais enquadrá-los em um repertório, em um contorno de objeto, em um perfil, dentro do universo imaginário daquilo que o discurso diz ser o louco, o indigenciado; normalizar a alteridade dentro do "espaço limitado e definido" da egocentricidade do discurso da loucura e da indigência.

A indigenciação é talvez a última tentativa de normatização do sujeito em ser inteligível, constituído, na tentativa de delimitar claramente a loucura e a indigência desses sujeitos do aqui e agora. Diferentemente, a indigência é a normatização do que outrora denominou-se de Lumpenproletariat, da forma-sujeito improdutivo, do sujeito indiferente e indiferenciado. De tal modo que, segundo as perspectivas industriais da Modernidade do século XVIII, o louco em si mesmo, o "sujeito" da mão-de-obra caótica como o indigente, o louco para o social, designaram uma generalização estabelecendo-o como um modo radical de sujeito improdutivo. Apenas nos sanatórios, o louco produz para o Estado, sem o saber, tornando-se dentro desse espaço de controle uma formasujeito no limite de sua deformação, aparado em suas arestas afiadas pelos psicotrópicos, sempre um amálgama na fronteira entre custo e benefício, em vista do lucro pela manutenção da loucura em seu estado pacífico; por sua vez, o indigente reproduz uma imagem modelo, como uma profunda exortação àquilo que não se deve ser; nessa perspectiva "industrial" $\mathrm{o}$ 
indigente nos ensina, por negação, que devemos produzir e, a reprodução para o Capital é um primado da norma. Em outras palavras, queremos dizer que a indigenciação é uma forma de discurso que suscita similitude entre loucura e indigência e que delibera práticas sociais de invisibilização e silenciamento que alcançam, sobretudo, sujeitos estereotipados como improdutivos, e, segundo Foucault (2002, p. 9), aqueles que se emolduram nas regiões discursivas "interditadas" da "sexualidade e da política".

Os indigenciados não despertam interesses como objetos do discurso, ocorrem na periferia dos discursos, mesmo que deste não escapem de todo. Os discursos, mínimos, representamlhos como opacidades; o silenciamento se efetiva pela insensibilidade temática - uma constante no Ocidente, um modo de seletividade e depois esquecimento. Se segundo Foucault, [...] a unidade do objeto "loucura" não nos permite individualizar um conjunto de enunciados e estabelecer entre eles uma relação ao mesmo tempo descritível e constante (2004, p.36), a indigenciação é uma tentativa de tomar como unidade um conjunto de enunciados que categorizam um tipo de discurso onde o objeto da indigenciação é nesse processo esquecido como função mesma de objetivação. Por causa disso, a indigenciação é também uma aporia, um contrassenso: falar e descrever minimamente aquilo que é o objeto do seu "interesse" no limite da mudez, da discretez, da sua fragilidade significativa, isso, para não suscitar um foco, sua atenção. A indigenciação do sujeito, em sua função hermenêutica, o enquadra negativamente ao associar seu modo de ser e estar às representações tendenciosas localizadas nas instancias da anormalidade: da improdutividade, da irregularidade sexual e disposições e de sua condição políticas contraditória.

\section{Silenciamentos e invisibilizações}

Foucault nos interroga ao utilizar um exemplo de um objeto quase hermético, a expressão bruta de uma alteridade, o sujeito louco: "se perguntássemos ao próprio ser da loucura, ao seu conteúdo secreto, à sua verdade muda e fechada em si mesma, o que se pôde dizer a seu respeito e em um momento dado" (2004, p.36). Nisso encontramos uma aporia dentro das condições de circularidade dos discursos, isto é, das

Problemata: R. Intern. Fil. v.6, n. 3(2015), p 111-128 ISSN 2236-8612 
possibilidades de chancela ou da interdição de um discurso verdadeiro ou que contenha uma verdade (Foucault, 2002), isto é, sempre o que se diz sobre o indigenciado é uma anulação da sua alteridade discursiva; o exemplo do anti-discurso que advém ao próprio louco é significativo para demonstrarmos aqui, em forma de hipérbole, como a indigenciação é, especialmente, a interdição de um discurso muitas vezes corporificado no próprio indigenciado que some na ausência do "seu" discurso ao mesmo tempo em que aquilo que é permitido saber sobre ele, o discurso que foi chancelado é outra coisa. Sobre o louco ou o indigente, por exemplo, a questão mais importante que levantamos é o que ele diz de si, da sua alteridade, para nós, não pode ser aniquilado pela linguagem, pelos discursos; sua existência como tal é em si mesma um discurso-outro, que por si só fala de tal maneira como uma expressão de autônoma absurda em face do mundo constituído, como sua negação radical dita em alfabeto próprio, que não se permite objeto, cujo rizoma permeia toda a humanidade, transcendendo o ser da linguagem ${ }^{6}$.

$\mathrm{Da}$ indigenciação como forma de silenciar, as possibilidades predicativas do ser do sujeito seriam fundadas através de práticas discursivas que sobre ele mesmo incidem, dizendo quem ele é e o que ele não é a partir dele mesmo, quando adotadas essas possibilidades predicativas; constitui-lhe a base de onde decorrem as formas de interferência da sua subjetividade, intervenção das suas vias de auto-objetivação ${ }^{7}$; isso se daria através de três condições de silenciamento: da ausência de discurso, do discurso como monólogo e do discurso não considerado. Estas condições decorrem de: a) os discursos tomam o ser como objeto-outro e constitui-lhe um aspecto ontológico definido, convencionalizado e padrão, aproximandoo do sujeito de um discurso e não como sujeito que discursa; b) aquilo que diz respeito ao sujeito em sua forma histórico inteligível, portanto, delimitada: o sujeito cidadão, o sujeito que trabalha, o sujeito democrático, o sujeito participativo, o sujeito político, são formas discursivas positivas, que não partem de nenhuma tentativa de suscitar ou "permitir" sua própria alteridade, mas de compendiá-lo, narrá-lo, consolidá-lo ratificálo e descrevê-lo em seu ego e seu alterego dentro dessa forma histórica. Isso visa circunscrever os sujeitos indigenciados a um discurso como monólogo; c) o sujeito do discurso - aquele que

Problemata: R. Intern. Fil. v.6, n. 3(2015), p 111-128 ISSN 2236-8612 
"toma para si" a autoria de um discurso -, subjetiva um conjunto de sentidos, por exemplo, sobre a loucura, "no grupo de todos os enunciados que a nomeavam, recortavam, descreviam, explicavam, contavam seus desenvolvimentos, indicavam suas diversas correlações" (Foucault, 2004, p.36); esta adoção categórica, este marco de orientação, como uma alteridade plástica, diz o que o sujeito-outro não é, por não considerar seu discurso. Temos aqui uma forma de subjetivação dos sentidos, adoção dos discursos sobre o que é um modo de ser e estar enquanto sujeito tal em sua "forma recente" (Foucault, 2007, p. 536). Assim sendo, a indigenciação é, antes de tudo, uma extrusão das possibilidades de identidade; é estar banido dentro mesmo de um sistema, de um topos, de um agrupamento humano. Nos três processos, o discurso atuar sobre a constituição dos sujeitos e traz a memória o labor das Moiras gregas $^{8}$, as fiandeiras que tecem a regularidade da vida, que as artificializam impedindo qualquer aspecto de contingencialidade.

Estão muito claros, no transcurso textual deste artigo, alguns exemplos de silenciamento e invisibilização. No entanto, como um ensaio, delimitamo-los aqui, por meio de algumas categorias de análise, no sentido em que a invisibilização estabelece em uma tríade: sujeito inconveniente, sujeito ignorado e o não-sujeito - tais que, baseado em Foucault, constituem o "sujeito elidido" (2007, p. 21). Com a licença pelos aspectos, sobretudo descritivos e propositivos desta sessão, pensamos que a invisibilização ocorre na condição onde o sujeito antes foi silenciado - ele perderia progressivamente a chancela de enunciação porque não comportaria, ao menos figurativamente, as condições discursivas como agente de uma verdade adquirida. Não possui um topos discursivo, ou seja, não foi subsumido numa instituição; não se justifica pela adoção de uma aparência legível e relacional a priori, por assim dizer, normal - naquilo que a compõe e que facilite, por meio de símbolos convencionalizados, sua associação a um grupo; nem currículo que legitimem sua modalidade de enunciação, ou quando sua compleição étnica desentoa da sua profissão e carreira. Com efeito, ao indigente restar-lhe-ia um discurso que possui como núcleo o apelo da mendicância, o pedido como discurso monótono, recorro não convincente; ao assalariado despolitizado ${ }^{9}$ a reclamação não considerada; ao que vivencia uma sexualidade característica a recusa, o abandono, e a noite Problemata: R. Intern. Fil. v.6, n. 3(2015), p 111-128 ISSN 2236-8612 
não com festa, mas como opacidade; ao opositor político a atribuição da infâmia, a demonização. Destarte, esse membro "desigualizado" entre iguais lembra-nos um palimpsesto, e faz circular de modo aparentemente inofensivo. O sujeito inconveniente institui, ou sobre ele é instituído, estigmas que pontuam significados de negação nas "regiões onde a grade é mais serrada e os buracões negros se multiplicam, [...] as regiões da sexualidade da política" (Foucault, 2002, p. 9) e ainda, a região do trabalho. Esse percurso transforma-o paulatinamente em um ignorado na paisagem cotidiana e, quando "visto de relance", desperta algum tipo de mal-estar, às vezes sutil, banal, ignorado, como no caso do indigente que, para alguns se assemelha mais a uma falha na arquitetura urbana ou um hiato no cotidiano social. O não-sujeito é uma contradição ou negação do sujeito constituído em seu caráter funcional - mesmo o louco, "organizado" num estado de loucura em que se pode manipular, dentro da orla do sanatório, é um sujeito sempre em constante transição com o não-sujeito; o indigente tirado de circulação normal (partindo daquilo que perceptivelmente deve circular como figura da normalidade), porque sua presença destoa demasiadamente da paisagem organizada ainda é recebido côo sujeito de alguma coisa; torna-se um não-sujeito quando sua presença caótica é vista com similar à ordem caótica dos lugares de arquitetura abandonada, topos onde a paisagem predominante é apresenta detrito, lixo etc. - e o que ele tem a dizer sobre tudo isso? Os modos de subjetivação nem o define bem nem "formata" eficientemente, isto é, ele não se sujeita facilmente a um regimento discursivo específico por sua localização existencial oscilante, às além das margens de sentido constituintes. O louco e o indigente, entes destituídos de discurso, são, por assim dizer, corpos-discursivos que "vociferam" inconveniências profundas, quando pressentidos no cotidiano.

\section{Formas de indigenciação do sujeito contemporâneo}

Talvez para além de hipóteses, pode-se encontrar os fenômenos que constituem um processo de indigenciação entre certos grupos de sujeitos, especialmente, aqueles diferenciados

Problemata: R. Intern. Fil. v.6, n. 3(2015), p 111-128 ISSN 2236-8612 
segundo certos "caracteres produtivos"10, isto é, sujeitos diferenciados e subsumidos ao grupo dos "improdutivos" - e não é regra geral que apenas o indigente típico seja um improdutivo; pode-se enquadrá-los ${ }^{11}$ - de forma sempre susceptível ao preconceito e ao equivoco, visto que percorre às ausências discursivas $^{12}$-, em categorias tais como exclusão e marginalização. Nesses aspectos, denominamos de processos de indigenciação excludentes e de processos de indigenciação marginalizantes $^{13}$. No âmbito dos discursos que agenciam as representações de trabalho produtivo ideais, são excluídas por esses discursos e práticas de indigenciação excludentes, pessoas que não se enquadram ao estereótipo ideal do sujeito producente: com efeito, são assinaladas discursivamente em categorias discriminatórias de idade, aparência, compleição ${ }^{14}$, etnia, grau de instrução (entre grau de formação acadêmico ${ }^{15}$ ) e ausência de letramento, tipos de produção ${ }^{16}$, poder econômico ${ }^{17}$, entre outros exemplos.

Os processos de indigenciação marginalizantes tomam forma a partir dos discursos que interditam certas práticas existenciais, a partir de interpretações morais majoritárias, religiosa, científica e filosófica, acerca de padrões normativos permitidos, dentro das "regiões da sexualidade e da política" (Foucault, 2002, p. 9) - no final das contas, são práticas existenciais não reconhecidas como corroborativas ao modelo de sujeito producente no âmbito das demandas contemporâneas do Capital, ou ainda, não são suscetíveis de generalização e de imitação para fins econômicos, como estereótipos consumíveis da cultura e da mídia (Kellner 2001; Gripsrud 2002; Paiva, 2002; Hall, 2013; Sauvageot, 1987), enfim, não podem ser enquadrados como força útil, corpo produtivo e submisso (Foucault, 2012, p. 29). Esse regime de marginalização - das características não aceitas como forma-sujeito ideal ${ }^{18}$ dentro dos aspectos da sexualidade e da política -, é mais contundente quando associado a outros aspectos culturais reprováveis em estereótipos de aparência, de compleição, de etnia, de idade, de grau de instrução, de poder econômico, etc. Destas condições, certamente podemos entender a indigenciação e talvez pensá-los como não-sujeitos ${ }^{19}$, visto que sua figura e seu conteúdo podem não enquadrarem-se em nenhum modelo satisfatoriamente constituído. 


\section{Algumas considerações acerca da indigenciação}

A indigenciação é uma prática de abandono premeditada, por vezes, estratégica - não apenas em seus aspectos de hiperexclusão econômica, isto é, da alienação social do bônus e do ônus econômico, por meio de um "tire-o da frente para que haja laissez-passer...", muito secundário aqui. A indigenciação consiste, especialmente, em um afastamento existencial da participação do mundo e do outro, quando nem sob a tolerância permite-se alguma aproximação; nem a possibilidade de uma tolerância aí exerceria algum tipo de diálogo no limite? Diante desta invisibilização e silenciamento, a ausência quase total de consenso não suscita um conflito porque, ao menos, uma das partes acredita num valor maior que a tolerância/intolerância, porém, valor maior assaz abstrato: um valor (de logro) compensador desta proximidade apenas física, regional, entre os sujeitos - como ocorre no caso do louco e raramente no caso do indigente ${ }^{20}$. Mas, não há tolerância ou intolerância nos processos de indigenciação - há, por assim dizer, uma indiferença, uma falta de interesse pelo outro. Assim, é de pensar-se que ele "coexista" em dimensões paralelas à realidade instituída, um espectro. Como pessoa humana, sua condição de indigência é o resultado direto das impossibilidades sociais que sobrecaem-lhe, ao tempo em que as tais distanciam-lhe do alcance visual, das possibilidades de inclusão: quando entrevisto, presença indesejável; por ser um ente desconsiderado, quase fantasma no cotidiano.

Acreditamos que a indigenciação decorre através das práticas discursivas de opacidade do sujeito que não interessamse em apreendê-lo em definitivo, mas deixá-lo em "suspenso", no limítrofe entre existência e inexistência, entre corpo-discurso que exorta-nos a não sê-lo e espectro do cotidiano, ser imperceptível - aqui, uma espécie de equilíbrio de interesses entre dizê-lo e não dizê-lo, entre clarificá-lo e obscurevê-lo. Portanto, mesmo construindo cotidianamente um distanciamento existencial, atravessam nossas subjetividades discursos e práticas de indigenciação tais que atuam, em maior ou em menor intensidade, atingindo-nos e determinando-nos como vítimas, ou como algozes reprodutores desse tipo característico de morte social.

Problemata: R. Intern. Fil. v.6, n. 3(2015), p 111-128 ISSN 2236-8612 


\section{Referências}

ADORNO, Theodor, W. Cultural Criticism and Society. In. Niel Levy e Michale Rothberg. The Holocaust - Theoretical Readings. Neuw Brunswick: Rutgers University Press, 2003.

ARISTÓTELES. Política. Tradução de Antonio Campelo Amaral e Carlos de Carvalho Gomes. Lisboa: Editora Vega, 1998.

DA SILVA, Wellington Amâncio. Aspectos da existência situada em Heidegger. Revista Logos \& Existência: Revista da Associação Brasileira de Logoterapia e Análise Existencial, v. 3, n. 1, 2014.

. DE MIRA, Feliciano José Borralho. Zizek e a violência da linguagem-O caso Charlie Hebdo como adormecimento do espaço simbólico dos sujeitos [Doi: 10.15440/arf. 2014.22995]. Aufklärung: revista de filosofia, v. 2, n. 1, p. p. 105-118, 2015.

ALVIM, Zukeika. Imigrantes: a vida privada dos pobres do campo. In. História da vida privada no Brasil. NOVAES, A. et ali. São Paulo: Cia das Letras, 2010.

DAVIS, Natelie Zemon. Sociedade e cultura no início da França moderna. 2. ed. Tradução de Mariza Corrêa. São Paulo: Paz e Terra, 2001.

FOUCAULT, Michel. A ordem do discurso. $8^{\mathrm{a}}$ Ed. Tradução de Laura Fraga de Almeida Sampaio. São Paulo: Loyola, 2002.

. História da Loucura. Tradução de José Teixeira Coelho Neto. 8. ed. São Paulo: Perspectiva, 2008 . Arqueologia do Saber. $7^{a}$ Edição. Tradução Luis Felipe Baeta Neves. Rio de Janeiro: Forense Universitária, 2010 . As Palavras e as Coisas. Uma arqueologia das ciências humanas. Tradução. Salma Tannus Muchail. Martins Fontes. São Paulo, 2007. - Vigiar e punir. Tradução de Raquel Ramalhete. São Paulo: Vozes, 2012 . História da Loucura. Tradução de José Teixeira Coelho Neto. São Paulo, Perspectiva, 2008

.A ética do cuidado de si como prática de liberdade. In: FOUCAULT, Michel. Ética, Política e Sexualidade: Ditos e escritos. Vol. V, 2. ed. Rio de Janeiro: Forense Universitária, 2006, p. $264-287$.

Problemata: R. Intern. Fil. v.6, n. 3(2015), p 111-128 ISSN 2236-8612 
GRIPSRUD, Jostein. Understanding media culture. London: Arnold, 2002.

HALL, Stuart. Representation: cultural representations and signifying practices. 2. Ed. London: Sage, 2013.

KELLNER, Douglas A cultura da mídia - estudos culturais: identidade e política entre o moderno e o pós-moderno. Bauru: EDUSC, 2001.

JAMESON, Fredric. Sobre os "estudos de cultura". In. Novos Estudos CEBRAP, nY39, julho, p. 11-48, 1994. (Social Text ${ }^{\circ}$ 34, 1993).

PAIVA, Raquel. O espírito comum - mídia, comunidade e globalismo. Rio de Janeiro: Mauad, 2003.

SAUVAGEOT, Anne. Figures de la publicité: figures $d u$ monde. Paris: PUF, 1987.

WOODWARD, Kathryn. Identidade e diferença: uma introdução teórica e conceitual. In: SILVA, Tomaz Tadeu da (org.). Identidade e diferença: a perspectiva dos estudos culturais, p. 7-72. Petrópolis, RJ: Vozes, 2000.

\footnotetext{
${ }^{I}$ Os autores objetivam transformar o discurso como monólogo em discurso entrevistável (discurso agora considerado), de modo a fundamentar o tipo de indigência aqui pretendido.

${ }^{2} E$ é aqui que reside um risco inerente a própria linguagem, a saber, a de constituir sentidos para o ser tornando-o forma-sujeito específica que funciona como um modelo muitas vezes hegemônico, um modelo que reforça os modos de ser e estar instituídos aos sujeitos numa sociedade que cristaliza o status quo, que impõe maneiras didáticas de pensar e se comportar constituindo assim um leque de formas-sujeitos que funcionam (perdoe-nos pelo exemplo assaz cartesiano) como engrenagens funcionais dentro de uma maquina.

${ }^{3}$ Os autores objetivam transformar o discurso como monólogo em discurso entrevistável (discurso agora considerado), de modo a fundamentar o tipo de indigência aqui pretendido.

${ }^{4}$ Grifo nosso.

${ }^{5}$ Para Foucault o sujeito é constituído através dos diversos discursos; nisso o sujeito é objeto do discurso; é objetivado por meio de constituições linguísticas específica, por exemplo, de uma área do saber: o sujeito da antropologia, o sujeito da história, o sujeito da pedagogia, o sujeito da psiquiatria, entre outros.

6 Expressão muito precisa anterior às expressões constituintes: "ser humano", "homem", "individuo", "sujeito", "ator", "pessoa”, etc. Tal expressão sintetiza a forma-sujeito primordial no Ocidente, advinda de

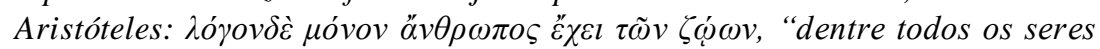
vivos, apenas o homem possui palavra”. ARISTÓTELES, 1998, a 9-10, p. 55.
}

Problemata: R. Intern. Fil. v.6, n. 3(2015), p 111-128 ISSN 2236-8612 
${ }^{7}$ Como questões gerais da Filosofia, as tradicionais: "de onde vim”, "para onde vou", se tornaram quase obsoletas e face do que a dificílima questão "o que sou", cada vez mais complexa - suscitando para muitos sujeitos pensantes aquilo que poderíamos denominar de ceticismo ontológico ou de outro ponto de vista muito suspeito, de niilismo existencial.

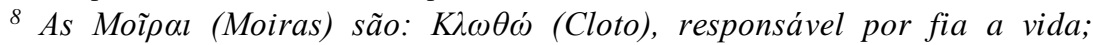

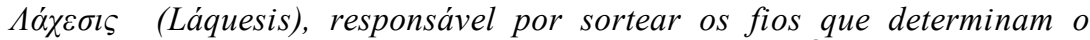
destino, é a divindade da "predestinação"; "A por cortar o fio da vida.

9 Despolitizado como aquele que não sabe reivindicar dentro de certas normas, que não protesta formalmente, isto é, que não insere sua exigência no âmbito do justificável, da legalidade, de maneira que materialize em seu discurso tanto a defeca da lei a seu favor como o merecimento dela por seus atributos funcionais, de desempenho como mão-de-obra. Despolitizado também no sentido de oposição e resistência, ou mesmo contra-hegemônico.

10 Por assim dizer, "modo de produção", onde se inclui as dimensões subjetivas e objetivas do trabalho.

11 Num âmbito cartesiano, enquadrar é sempre catalogar, prender, fixar, cristalizar, esvaziá-los de sentidos, visto que, neste caso, sentidos ocorrem em uma dinâmica contextual no mundo, lugar dos acontecimentos ligados aos sujeitos, como aquilo que os move e como aquilo que estes elaboram, mediam, compartilham.

12 O indigente é diferente do louco, em cujo "sujeito" foi construído um papel econômico nos sanatórios através do regime de dependência e, por isso mesmo, interessam-se de saber o que ele é por ele mesmo, pelas tentativas clinicas de transladar seu discurso hermético. Ao indigente não se permite um discurso, nem a este é suscitado interesse. Percebemos no indigente as ausências de um discurso - muito embora ele seja mesmo o próprio discurso, um corpo discursivo de um discurso outro.

${ }^{13}$ De fato, exclusão e marginalização aparentam ser uma mesma coisa. No entanto, aqui, queremos considerar exclusão como o afastamento dos sujeitos dos seus próprios direitos dentro da tipologia do trabalho desvalorizado, muito embora eles estejam dentro da sociedade, porém, experimentando condições de indignidade; os sujeitos excluídos podem despertar interesses de exploração - apesar de pouco considerados - estão "à vista", são observados, entram nas estatísticas, escreve-se sobre eles. O processo de marginalização é, sobretudo, mais radical, pois, expulsa os sujeitos do centro para a margem da sociedade, silenciando-os $e$ invisibilizando-os. Sujeitos marginalizados geralmente são postos numa dimensão social espectral. Antes, eles são enquadrados categoricamente nas tipologias negativas, portanto, não aceitáveis, da sexualidade e da política.

${ }^{14}$ Tomamos aparência como à figura culturalmente constituída pelos trajes $e$ ornamentos que apontam para culturas periféricas; compleição como uma constituição genética que aponta para feições étnicas diferentes do biótipo europeu (homem +jovem +anglo-saxão/ariano).

${ }^{15} \mathrm{O}$ caso dos professores das séries iniciais no Brasil desmistifica o aspecto majoritário da variável condicionante "formação acadêmica" como mérito, conditio sine qua non de ascensão social e econômica. Aqui, nos parece, que

Problemata: R. Intern. Fil. v.6, n. 3(2015), p 111-128 ISSN 2236-8612 
um tipo de produção "aquém" das demandas materiais imediatas do Capital financeiro instituído, denotaria e conotaria algum tipo de improdutividade?

${ }^{16} \mathrm{Na}$ contemporaneidade, nas perspectivas deontológicas do trabalho capitalista, por exemplo, a adjetivação "sujeito improdutivo" não corresponderia ao sujeito que nada produz, como o indigente; certamente a nulidade social do ser do sujeito improdutivo decorra da ausência de uma forma de produção monetária visivel ou ostentativa, justificada por meio dos seus discursos específicos. Aí a materialidade do discurso estaria, por exemplo, contida na forma mesma dos bens materiais - em sua aura de valor em face de classe social e do fetiche da marca (grife) -, adquiridos dentro de regras e de mérito específicos em vista de status social e, a partir de representações que legitimam a posse de bens, tais como certos cargos e profissões de grande poder no imaginário social - tais ofícios constituem em si a materialidade do discurso da forma-sujeito-produtivo. A ausência de possibilidade de produção é, pois, a ausência de certos bens materiais e da alcunha de certas profissões financeiramente "invalidadas" socialmente: Zé artista plástico, Maria feirante, Pedro artesão, José das esculturas, etc. percebamos aqui a ausência dos títulos antes do nome próprio e da troca do sobrenome pelo ofício.

${ }^{17}$ Aqui simplesmente como a capacidade visível de obtenção e consumo de bens.

18 Aqui, lembramos de Adorno: "escrever poesia depois de Auschwitz é um ato de barbárie” (2003, p. 281). Qualquer escrita é dificílima em face das vítimas, há uma ousadia que envergonha o escritor, seja de poesia, de prosa ou de texto científico. Porém, a denúncia é uma condição, talvez, de nos envergonharmos menos. No Brasil, temos o nosso "Acontecimento" que impossibilita a poesia e, tratar dele aqui nos envergonha porque a escrita é sempre fria, esvaziativa, enquadrativa, generalizante e de pouco alcance em face da totalidade dos fatos. Fazemos aqui movido pelo desejo de denuncia, mas antes de tudo, pedimos desculpas por fazê-lo do nosso "lugar de conforto" acadêmico...

${ }^{19}$ E há alguns aspectos libertários "em erupção”, entre o limitrofe da crise existencial e social e a satisfação de si.

${ }^{20}$ Na Antiguidade a prática da caridade considerava menos o indigente e mais o temor aos deuses, visto que a caridade funcionava para aplacar sua fúria. Na Idade Média o indigente também não era propriamente o sujeito central desta prática, mas um meio de se obter o perdão e a misericórdia de Deus. $O$ indigente minimamente atendido em sua necessidade servia mais para justificar o sujeito caridoso. 